DEPARTMENT OF ECONOMICS, MANAGEMENT AND STATISTICS

UNIVERSITY OF MILAN - BICOCCA

DEMS WORKING PAPER SERIES

Human Smuggling and Intentions to Migrate: Global Evidence from a Supply Shock along Africa-to-Europe Migration Routes_

Guido Friebel, Miriam Manchin, Mariapia Mendola, Giovanni Prarolo

No. 375 - December 2017

Dipartimento di Economia, Metodi Quantitativi e Strategie di Impresa Università degli Studi di Milano - Bicocca

http://dems.unimib.it/ 


\title{
Human Smuggling and Intentions to Migrate: Global Evidence from a Supply Shock along Africa-to-Europe Migration Routes*
}

\author{
Guido Friebel $^{\dagger} \quad$ Miriam Manchin ${ }^{\ddagger} \quad$ Mariapia Mendola ${ }^{\S}$ Giovanni Prarolo
}

December 6, 2017

\begin{abstract}
Africa-to-Europe irregular migration depends heavily on human smuggling services. The demise of the Gaddafi regime in 2011 marked the end of a bilateral agreement between Italy and Libya and opened the Central Mediterranean Route for irregular border crossing. How did this remarkable increase in human smuggling services affect migration intentions in the rest of the region? This paper isolates a causal impact by exploiting the spatial dimension of the smuggling network and its change over time, which produced a heterogeneous decrease in bilateral migration distances between countries in Africa and Europe. We use this source of variation and a novel dataset of bilateral distances along irregular land and sea routes, combined with cross-country survey data on individual intentions to move from Africa to Europe between 2010 and 2012. Netting out pair- and country-by-time-specific fixed effects, we find a large negative effect of distance along smuggling routes on individual migration intentions. Shorter distances increase the willingness to migrate especially for youth, (medium) skilled individuals and those with a network abroad. The effect is stronger in origin countries not too far from Libya and with weak rule of law.
\end{abstract}

JEL codes: K23, K42

Keywords: International Migration, Human Smuggling, Illegal Migration, Libyan Civil War

\footnotetext{
${ }^{*}$ We thank Francesco Amodio, Thomas Bauer, Francesco Fasani, Jennifer Hunt, Joan Llull, Luigi Minale, Gianmarco Ottaviano, Giovanni Peri, Hannes Muller, Dean Yang and seminar participants at SITE-Stockholm School of Economics, EBRD-London, IAE Barcelona, Montpellier Business School, University of Bologna, CReAM/RWI Workshop on the Economics of Migration, EPCS-Meeting at CEU in Budapest and the Development Economics and Policy Conference in Goettingen for helpful comments and suggestions. We are grateful to Jan Luksic and Giulia Vattuone for excellent research assistance and to Sara Lazzaroni for help with geocoded data. The usual disclaimer applies.

${ }^{\dagger}$ Goethe University Frankfurt, CEPR and IZA Email: gfriebel@wiwi.uni-frankfurt.de.

${ }^{\ddagger}$ University College of London. Email: m.manchin@ucl.ac.uk.

${ }^{\S}$ Università di Milano-Bicocca and IZA. Email: mariapia.mendola@unimib.it.

`Università di Bologna. Email: giovanni.prarolo@unibo.it.
} 


\section{Introduction}

Worldwide migration pressure is expected to rise with growing demographic and economic differences between developed and developing countries. Yet, legal migration channels are becoming increasingly scarce and congested, destination countries are investing in administrative and physical barriers, and irregular migration has become one of the most controversial public policy items in many of the destination countries.

Apparently, building up barriers has done little to decrease people's willingness to move across international borders (Docquier et al., 2014); rather, a new multi-billion USD industry has emerged which engages in smuggling and trafficking migrants. ${ }^{1}$

The traditional migration push-and-pull factor research and policy framework fails to take into account the growing role of the smuggling industry, by now the third largest transnational crime, following drug and arms trafficking (Shelley, 2014; UNODC, 2011; Salt, 2003). Some progress has been made by incorporating the smuggling industry in the theory on international migration (Friebel and Guriev, 2006, 2012; Tamura, 2010; Auriol and Mesnard, 2016), with drastic effects on policy conclusions about border controls, deportation and the provision of legal channels of migration. However, by its clandestine nature, reliable data on the supply of human smuggling are scarce. It is hence notoriously difficult to empirically assess the effect of the smuggling industry on people's intention to migrate, and on the magnitude of migration flows and its composition.

We aim to contribute to filling this gap of causally interpretable evidence on the effect of the smuggling industry by exploiting the demise of the Gaddafi regime in 2011 as a natural experiment through which the network of migration routes offered by the smuggling industry extended - in paticular by opening up the Central Mediterranean Route (CMR) - thus reducing the distance between pairs of origin and destination countries in a very large portion of the world, namely Africa, Near East and Europe. Distance is a proxy for the transport costs of moving (see for example Disdier and Head (2008) looking at trade and Lucas (2001) on migration). We use this exogenous shock to smuggling distance across contry-pairs in a gravity analysis of the impact on individual migration intentions before and after 2011. Our approach is similar to Feyrer (2009), who uses the closure of the Suez canal as an exogenous shock to sea distances to identify the effect of transportation costs on trade (see also Pascali (2017)). We thus employ a gravity approach and construct bilateral, time varying migration distances along smuggling routes between the global set of country pairs. We estimate the impact of a change in distance on individual bilateral migration intentions, while controlling for pair fixed effect which account for all static differences and proximity

\footnotetext{
${ }^{1}$ Technically speaking, trafficking entails that migrants do not have agency but are subject to some coercion, while coercion is absent in smuggling. Yet, many crimes are committed against migrants during the smuggling process such that the distinction may have little bite. Furthermore, statistical data often do not clearly distinguish between irregular migration via trafficking or smuggling (UNODC, 2011). Hence, in our paper, we will use the term smuggling for the process of irregular migration, and the services provided and the crimes committed by the agents involved in the industry.
} 
between country pairs. Hence, identification is achieved through changes in distance along irregular routes, which are fully controlled by smugglers in Africa, so that the effect is coming entirely through changes in the costs of irregular migration. We find a large negative effect of the distance connecting country pairs along illegal routes on individual migration intentions. Shorter distance, along an extended irregular smuggling network, increases the bilateral migration intentions especially for youth, (medium) skilled individuals and those with a close network abroad.

Our approach relies crucially on our interpretation of the 2011 collapse of the Gaddafi regime, and in general the turmoil that hit North Africa in 2011, as a natural experiment whose unintended side effect was an extension of the supply of smuggling services. This interpretation warrants some more explanation and institutional background. Smugglers transport migrants from the entire African continent to Europe, offering their services to irregular migrants only. The increase in border-related bureaucracies and control, coupled with poor infrastructures, lack of transportation means and the complexity of the trip in Africa (e.g. passing through the desert or crossing the Mediterranean), make it very likely for prospective migrants to use smuggling services. In other words, the availability of smugglers is a necessary condition for South-North migration. At the same time, smugglers only go where customers are, i.e. along the network of smuggling routes: smugglers are therefore also a sufficient condition for illegal migration. This makes African irregular migration qualitatively different from the one occuring between Mexico and the US, where the smuggling market is concentrated mainly at the border and hence its spatial dimension plays a minor role. ${ }^{2}$

Major sea routes of Africa-Europe irregular migration include the CMR, the East and the West routes. While nothing happened to other routes in the time period under study, the CMR had been closed by the 2008 'Friendship Treaty' with Italy, which allocated significant funds to fight illegal migration, via the Mediterranean. However, border controls and migrants' retention in Lybia collapsed in 2011. ${ }^{3}$ As documented by Micallef (2017), in the absence of policing and border controls on the Lybian side of the Mediterranean, a large-scale smuggling business emerged almost immediately. Africa-to-Europe migration routes form a network (with hotspots as nodes) and the opening of the CMR made many nodes in the network closer than before, potentially easing the prospective migrants' chances to move northward. ${ }^{4}$ According to official statistics, the number of people crossing the CMR was 4,500 in 2010, while in 2011 it increased by a factor of almost 15, reaching $64,300 .{ }^{5}$ It is crucial for our research design that we use this shock, but do not focus on the shock itself. In fact we exclude from the analysis the year in which the shock happened (2011), and, more importantly, the countries of the region that were directly involved in the Arab spring. We

\footnotetext{
${ }^{2}$ Most of the literature on illegal migration has focussed on irregular crossing at the Mexico-US border (e.g., Spilimbergo and Hanson, 1999; Hanson, 2004; Gathmann, 2008; Dolfin and Genicot, 2010).

${ }^{3}$ On February 26, 2011, the Treaty on Friendship, Partnership and Cooperation signed between Italy and Libya on August 31, 2008 was actually suspended by the Italian government.

${ }^{4}$ Hotspots are those cities, towns or places where the physical interactions between smugglers and migrants take place, such as getting in contact and paying the amount, starting a journey, changing the transportation mean, etc.

${ }^{5}$ http://frontex.europa.eu/trends-and-routes/centralmediterranean-route/
} 
thus evaluate the global, country-pair, unintended effects of a supply shock to smuggling services as a result of the opening up of the CMR. ${ }^{6}$

For our empirical analysis we combine a novel geocoded data set of irregular migration routes from Africa and the Middle-East towards Europe, with a large, repeated cross-country survey data from 2010 and 2012 on individual migration intentions between origin and destination countries from Africa and the Middle East to Europe. This dataset also includes many household and personal characteristics. Using intentions instead of actual migration, for our purpose, is likely to be an advantage because they include regular but also irregular potential migrants, while actual migration data have substantial measurement issues because of the clandestine nature of irregular migration. Furthermore, several contributions have shown that there is a high correlation between intentions and actual migration (Creighton, 2013; van Dalen and Henkens, 2013; Docquier et al., 2014; Manchin and Orazbayev, 2016).

Formal identification is achieved by using the time variation in distance along smuggling routes between origin and destination countries, which resulted from the opening of the CMR, to estimate the impact on people's intention to move from Africa and the Middle-East to European countries. The inclusion of country-pair fixed effects, together with country-by-time fixed effects, control for country specific push and pull migration determinants, including geographical distance, bilateral agreements, economic, language and cultural proximity. Therefore, the impact of the change in distance estimated in our analysis directly captures the impact of change in transport costs of moving along smuggling routes. Moreover, we investigate heterogeneous effects by interacting our measure of supply of human smuggling services (proxied by the time-varying migration distance) with individual- (and country-) level characteristics. This is intended to shed light on the individual sensitivity to smuggling costs or to the incentive for illegal migration. By finding a negative average impact of distance on migration intentions, with heterogeneous effects across the population, our results are consistent with a model where the migration decision depends on transportation costs, i.e. smuggling costs, which rise with distance. The cost of illegal border crossing, though, is heterogenous across the population so that individuals with a lower time-equivalent cost of moving (e.g. with higher human capital) are more willing to migrate.

Section 2 and 3 describe the background context. Section 4 outlines our theoretical framework. Data are presented in Section 5 while Section 6 describes analytically the aggregate setting. Section 7 presents the empirical strategy and results are reported in Section 8. Section 9 concludes.

\footnotetext{
${ }^{6}$ To illustrate the magnitude of the effect of the shock, consider for instance that the distance along smuggling routes between Ethiopia and Norway decreased by more than 2,000 km between year 2010 and 2012 .
} 


\section{Background literature}

Migration is a process that is costly both in terms of money and time and which involves substantial risks. Such a decision depends on supply and demand factors, and individual specific factors. On the supply side, the migration choice is driven by sizeable cross-country disparities in economic (and non-economic) opportunities (Sjaastad, 1962; Borjas, 1999; Clemens, 2011). On the demand side, cross-border flows are shaped by migration policies at destination, such as border controls, employer sanctions, deportation policies, amnesties (e.g., Spilimbergo and Hanson, 1999; Ortega and Peri, 2013; Mayda, 2010). By taking an aggregate perspective, the extant literature is consistent in showing that both supply and demand factors, measured by cross-country and bilateral characteristics, significantly drive international migration flows - even though economic incentives and labor market conditions at destinations appear to matter significantly more than restrictive policies to migration. Yet, the latter include measures to control legal border crossing but do not exclude the possibility of migration through illegal channels. In fact, over the last decades legal channels for migration have dried up giving rise to irregular migration flows, which are made possible by a concomitant rise of a profitable market for migration (Hanson, 2007; Friebel and Guriev, 2006; Gathmann, 2008). Hence, the push and pull framework may not suffice to analyze modern irregular migration without considering the role of the smuggling market on the decision to migrate irregularly.

Due to the longstanding phenomenon and relative availability of information, most of the literature on illegal migration has focused on the irregular crossing of the Mexico-US border. There is evidence that over three decades (1970-2000) there has been a concomitant increase in both illegal migration (measured by different proxies) and border enforcement in the US (Hanson, 2004). Spilimbergo and Hanson (1999) use data on alien apprehensions by the U.S. Border Patrol to estimate the elasticity of illegal migration to both border enforcement (measured by border patrol linewatch hours) and Mexico/US wages. In addition, there is evidence that among those who illegally cross borders, the demand for smugglers has grown commensurate with rising border control. The share of unauthorized U.S.-Mexico border crossers using intermediaries or smugglers has been estimated at about 80 percent in 1990 to over 90 percent in the mid to late 2000s (Jandl, 2007; Dolfin and Genicot, 2010; Martin and Miller, 2000).

According to theory, expected lifetime benefits from migration, net of moving costs, are not homogeneous across individuals such that some people 'self-select' into migration more than others. Indeed, migrants differ from non-migrants with respect to their personal characteristics (e.g. age, gender), skills, education and socio-economic background. These differences affect their ability to bear migration costs and to match potential immigration policy requirements in the host country (Borjas, 1987; Chiquiar and Hanson, 2005; Beine et al., 2011). In particular, there is evidence that individuals with higher observed and unobserved skills have lower (time-equivalent) migration 
costs. This is due to the existence of either licit or illicit migration intermediaries. On the one hand, individuals migrating legally must satisfy many bureaucratic requirements, involving extensive paperwork and repeated interactions with origin service providers and destination immigration authorities. More educated individuals may be able to meet these requirements more easily. On the other hand, there is a large industry for illegal migration that provide smuggling services to cross the border, including physical transportation to a (safe) location at destination and counterfeit residency documents (Orrenius, 1999). Again, relatively skilled or higher-wage individuals may require fewer effective labor hours to migrate through illegal channels between developing and developed countries. Overall, the existence of a market for migration services suggests that the time-equivalent cost of migration will be higher for individuals with lower hourly wages (since it takes them higher labor hours to pay for these services) (Chiquiar and Hanson, 2005). Hence, to what extent changes in the supply of smuggling services affect the size and composition of cross-country relocation depend on differentials in the elasticity of demand for such services across heterogeneous individuals.

Despite the growing interest and policy concerns on irregular migration, there is a small economic literature on the role and structure of the clandestine migration industry. Friebel and Guriev (2006) examine the interaction between deportation policies and debt-financed illegal immigration in a model where wealth constrained individuals repay their debt to smugglers by entering into contracts that are easier to enforce in the illicit sector. Hence, they show that deportation and border control policies may have a significant effect on the size and compositiong of illegal migrants through the response of the smuggling market (see also Tamura (2010) and Auriol and Mesnard (2016) on the interaction between the smuggling market and policy measures). From an empirical standpoint, the main challenge to the analysis is the lack of data on illicit phenomena that are, by their own nature, unobservable. While focusing on human trafficking, (Mahmoud and Trebesch, 2010) use IOM household survey data from Belarus, Bulgaria, Moldova, Romania and Ukraine to show that migrant families are more likely to have trafficking experience in regions with large emigration flows. They argue that this is the case because in such regions recruitment costs for traffickers are lower and self-selection of customers (migrants) is likely to be negative. Other papers examine the interplay between human trafficking, law enforcement and the level of corruption in both origin and destination countries, pointing however to traffiking victims as coming from middle-income countries rather than poor contexts (Akee et al., 2014; Cho et al., 2014). Most recently, by using unique survey data from Senegal, Arcand and Mbaye (2013) investigate how individual preferences, i.e. risk and time preferences, influence illegal migration intentions and the willingness to pay a smuggler in an African context. The study is based on direct interviews to 400 individuals in Dakar, which involve choices in hypothetical situations, and finds that the likelihood to choose illegal over legal migration is an increasing function of the intertemporal discount rate, 
an ambiguous function of risk-aversion and a decreasing function of the price of illegal migration. ${ }^{7}$

Overall, there is still paucity of systematic and rigorous evidence on the extent to which, all else equal, the supply of smuggling services affects the individual likelihood to respond to the incentive for irregular migration. This is of interest since, both on a theoretical and empirical ground, the effects of economic factors or policy measures on the migration decision problem depend crucially on whether or not the actual market for migration is considered.

\section{South-North illegal migration}

With rising border controls and immigration enforcement activities, economic returns to the smuggling business have been growing over the last decades and South-North migration routes have increased in lenght, difficulty and riskiness in different part of the world (Jandl, 2007; Gathmann, 2008). For African migrants without European travel visas, the most viable way to move northward is that of travelling through the trans-Saharan and maritime routes. ${ }^{8}$ Migration routes are typically shaped on old ones used by caravans and during transhumance through the desert, while new routes have been slowly developing based on smuggling competition and human exploitation. ${ }^{9}$

Libya remains the major hub of people migrating towards Italy and the main spot of departure for the European dream. During the Gaddafi regime until 2010, the central Mediterranean route was essentially a closed route for irregular migration, since Libyan borders were heavily patrolled by local and international police. In 2008, Italy signed the Friendship Treaty with Libya with the aim of investing in border control and fighting irregular migration, especially via sea. Article 19 of the Treaty, signed by Gaddafi and Berlusconi, called for two things in particular. On the one hand, the approximately $2000 \mathrm{~km}$ of Libyan coast are to be patrolled by mixed crews on patrol boats provided by Italy. Six patrol boats were supposed to enter into operation in May 2009. On the other hand, Libyan land borders were to be controlled by a satellite detection system jointly financed by Italy and the European Union. Yet, in 2011, a wave of sudden protests and uprisings, known as the Arab Spring, shook up the socio political environment of some African Mediterranean countries. Popular revolts started in Tunisia in December 2010 and in 14 months rulers in Tunisia, Egypt, Libya and Yemen had been forced from power. In particular, in 2011 a significant amount Tunisian people left the country through the central Mediterranean route, while as from late 2011, the Gaddafi autocratic regime collapsed and Libyan borders suddenly become

\footnotetext{
${ }^{7}$ They further show that potential illegal migrants place a high monetary value upon migration and have a high utility gap between migrating and remaining in Senegal (the willingness to pay for smuggling is an increasing function of the lump-sum payment necessary to make the individual stay put in Senegal).

${ }^{8}$ According to Europol-INTERPOL 2016, more than $90 \%$ of the migrants coming to the EU are facilitated, mostly by members of a criminal network. Not all migrants are actually able to go beyond North Africa, putting their journey to an end in one of the Mediterranean coastal countries (especially in Libya and in Maghreb, where nowadays almost 2 millions of irregular migrants live). Yet, an increasing share of the migration stream uses Mediterranean sea routes.

${ }^{9}$ see iMap website (http://www.imap-migration.org/.
} 
available to undocumented migrants.

Figure 1: Monthly pattern of illegal migration across the Central Mediterranean Route

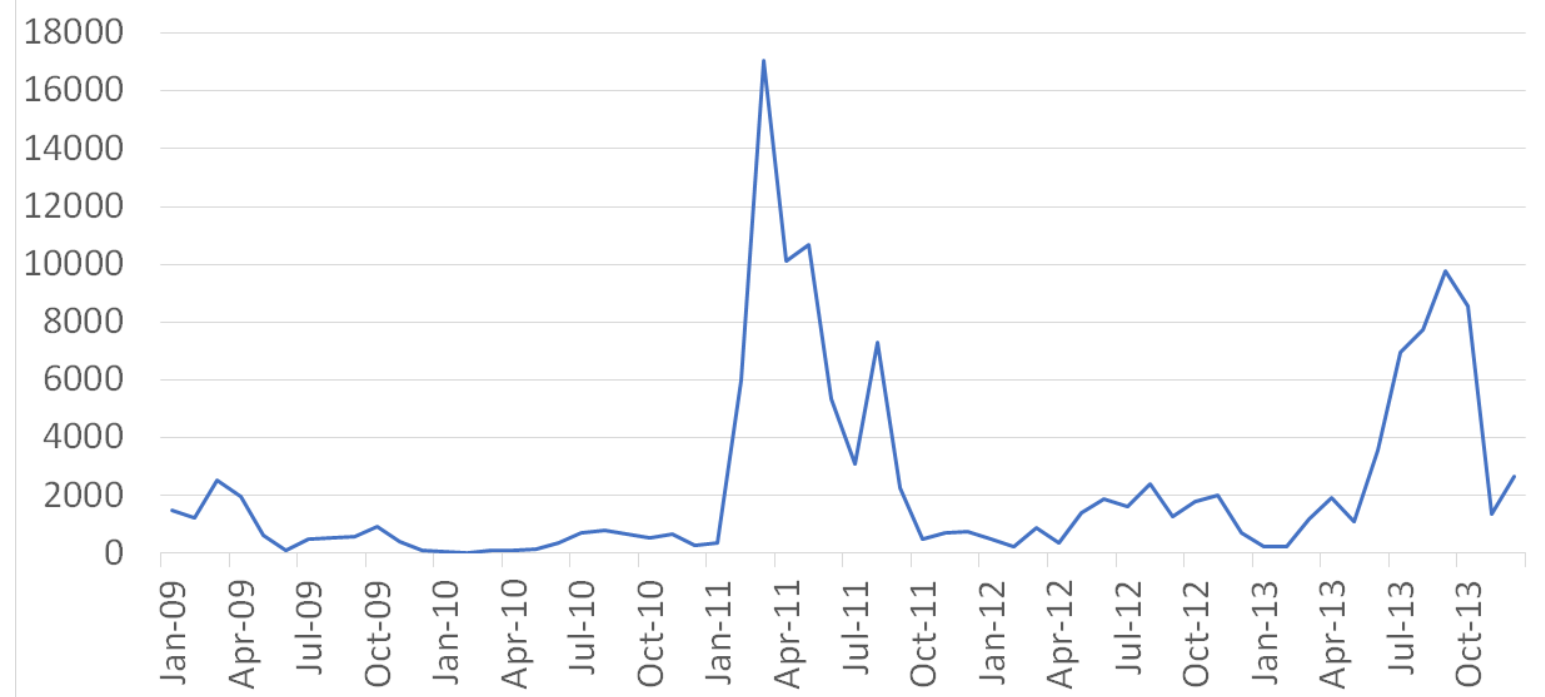

Notes: The figure shows the monthly number of detected illegal migrants (i.e. detected border crossing) arriving in European territory across the Central Mediterranean Route in the period 2010-2012. The shaded area represents year 2011, which will not be used in the econometric analysis. Source: Frontex)

Figure 2: Detected illegal migrants across the Central Mediterranean Route by country of origin

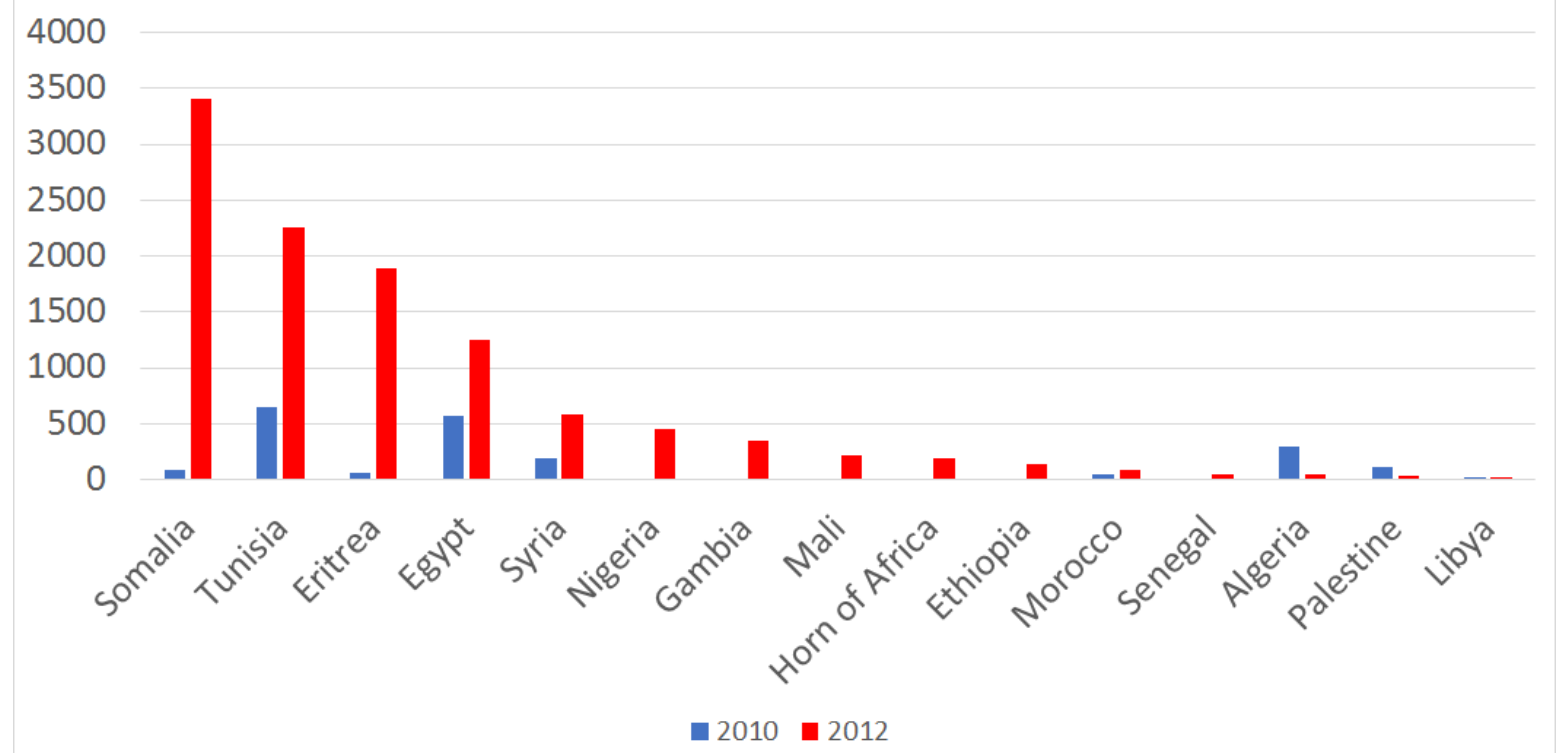

Notes: The figure shows the number of detected illegal migrants (i.e. detected border crossing) arriving in European territory across the Central Mediterranean Route from selected origin countries in years 2010 and 2012. Source: Frontex)

By using data collected by Frontex ${ }^{10}$ on detected migrants across the CMR, Figure 1 shows a

\footnotetext{
${ }^{10}$ Frontex is the European Authority in charge of border management and control of the European Schengen Area, in coordination with the border and coast guards of Schengen Area member states. They collect montly data on irregular migrants arriving in Europe through major South-North migration routes, which are Central Mediterranean, Circular route from Albania/Greece, Eastern Land Border, Eastern Mediterranean, Western African, Western Balkans, Western Mediterranean. See http://frontex.europa.eu/
} 


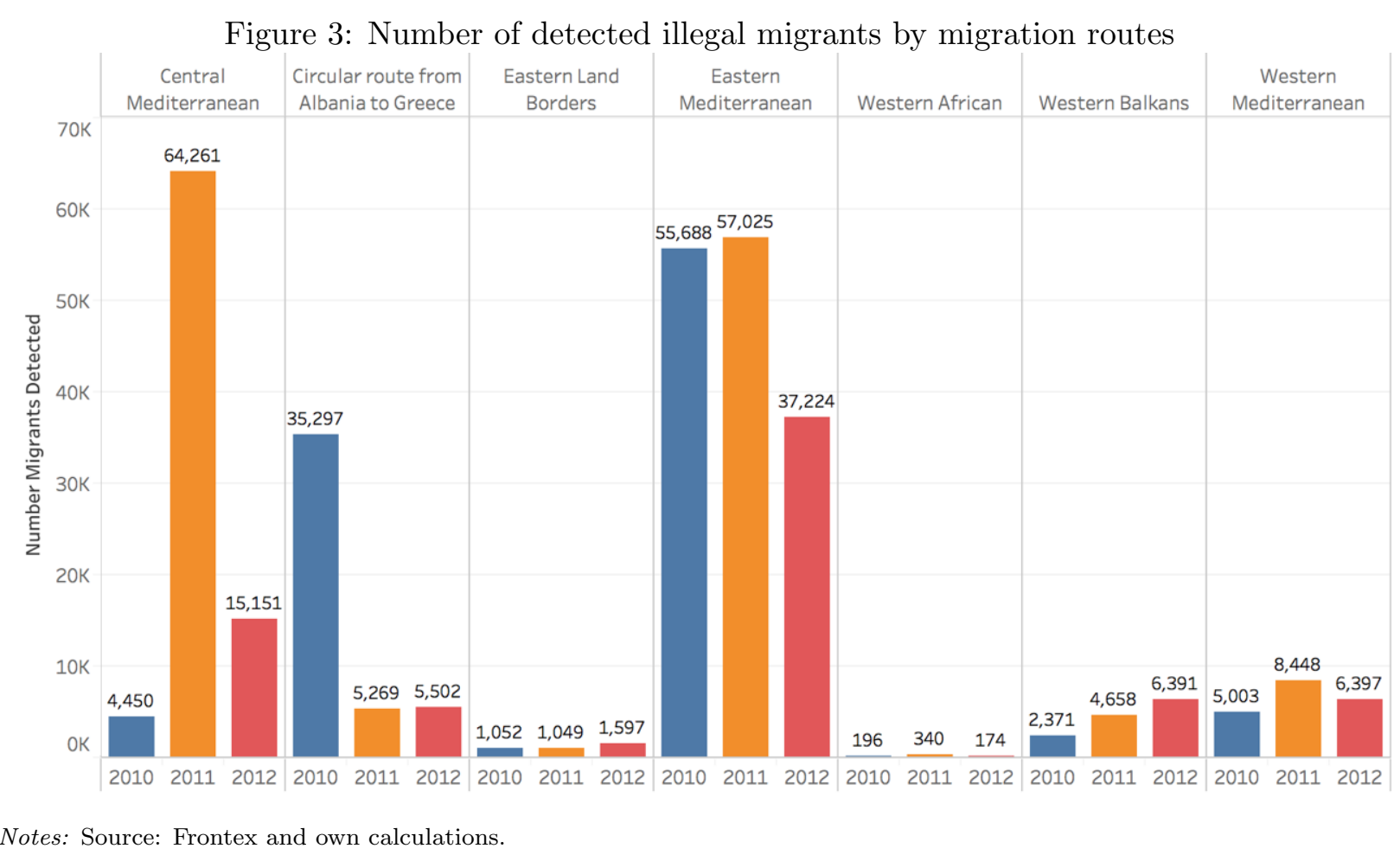

flat and close to zero pattern in irregular migration across that route for the year 2010, a large spike in 2011 and a lower average level in 2012, which is still around three times larger than that in 2010. In particular, the spike in 2011 comes from many people from sub-Saharan Africa who originally left their country of origin to work in Libya and have fled from the country to Europe as soon as the regime collapsed and sea routes were no more controlled, so that the smuggling industry boomed in the central Mediterranean route.

Figure 2 shows variation in detected illegal migrants by origin country crossing the central Mediterranean route before and after the collapse of Libyan regime. For many countries in the sample we see large and increasing absolute numbers. Importantly, some of these countries are not close to Libya (see for example Somalia, Eritrea, Syria and Nigeria), suggesting that Libya, since 2011, became plausibily the main human smuggling hub connecting African countries to European ones.

Finally, in Figure 3 we employ Frontex data to compare the use of different smuggling routes, as measured by detected illegal migrants. The figure shows a signifcant increase in the use of the CMR after 2010, a decrease in the use of the 'Circular route from Albania to Greece' (which is less relevant for our setting), while there is no much time variation in the use of the remaining migration routes. ${ }^{11}$ Overall, qualitative evidence reported above points to the fact that, after the demise of the Lybian regime and the associated spike in migration in 2011, CMR re-opened while

\footnotetext{
${ }^{11}$ It is worth noting that information on fatalities along remote land routes are impossible to gather systematically so measurement of riskiness is subject to a lot of measurement error.
} 
no major shocks occurred in the rest of the region (we provide more compelling evidence on this in Section 6). This translates in an increase in the supply of smuggling services, with a potential sudden decline in the average smuggling market prices.

\section{Theoretical Framework}

We here provide a framework meant to provide guidance for the empirical research carried out in the next sections. Our empirical analysis absorbs the push and pull factors that are predominantly considered in the literature by the country-pair

xed effects and the origin- and destination-country-by-time fi

xed effects. We have a focus that is dierent and which can be summarized in three questions: (i) Who is more likely to utter intentions to migrate? (ii) How would a reduction of distance as brought about by an exogenous extension of the smuggling network affect bilateral migration decisions? (iii) How would the reduction of distance interact with household and individual factors?

Model description: To shed light on what to expect empirically, consider the decision of a potential irregular migrant as determined by the following objective function:

$$
\begin{aligned}
& \max (1-M)\left(w_{o}+B_{o}(H H)\right)+M w_{d}(H, N)-M c(H, G, D) \\
& \text { s.t.W } \geq k D s
\end{aligned}
$$

Here, $M$ is an indicator variable which is 1 if the individual migrates and zero otherwise. The first term represents the utility of a person when deciding not to migrate, and follows standard assumptions in the literature on migration. At the origin country $o$, the individual receives a utility of his or her labor income $w_{o}$ (here, index $o$ stands for the origin country) which is assumed not to differ much in terms of individual characteristics, for a number of reasons. In many African countries, (i) unemployment is high, (ii) returns to education low, and (iii) much of the labor income stems from self-employment or agricultural employment. ${ }^{12}$

Benefit, $B_{o}$, is meant to capture the compensating differentials that would be lost upon migration, in particular, those related to social networks in the origin country. It is also meant to capture the benefits of using time for household work, which would be lost upon migration. $B_{o}$ can in sum be positive or negative, but from the discussion above it seems likely that the term is positive, however it is reasonable to assume it to be a function of household characteristics HH. For instance, we would expect it to be larger in households with a high ratio of dependent household members over household members in working age.

The second term stands for the labor income $w_{d}$ of the individual upon migration, i.e. in a destination country $d$. While the time varying country effects are soaked up by fixed effects, we consider the level of education $H$, and whether or not the migrant can rely on a social network

\footnotetext{
${ }^{12}$ In principle, one could hence omit $w_{o}$ from the equation as most of it will be soaked up in the country fixed effect.
} 
in the destination country ( $N$ is a binary variable). The latter reflects the importance of social connection as emphasized in the literature. In principle, one could also consider the wage to depend on personal characteristics, like age or gender, however these proles tend to be rather depressed for migrants in destination countries, in which most migrants, if at all integrated in the labor market, earn similar wages in the low-skilled sector. ${ }^{13}$

While all of the above ingredients would be present in an analysis of legal migration, the costs associated with irregular migration (the third term in the equation) are more intricate. The cost term, and the budget constraint (see below) are also likely to bear most potential for interesting heterogeneous effects. As in any rational choice theory of migration there are monetary costs that are reasonably assumed to be increasing, and, potentially, concave in the distance between origin and destination country. However, the clandestine nature of irregular migration brings to the forefront the non-monetary components of the cost of migration for which a number of personal characteristics may play a role, in particular, education $(H)$, and gender $(G)$. Different types of people may not only be exposed to different types of risks when they migrate, but they may also associate different degrees of importance to these risks. While we are agnostic about potential hypotheses about the partial derivatives of the cost function with respect to individual characteristics and would rely on the empirical analysis to learn more, we assume that $\mathrm{c}$ is (at least in some range) decreasing in education because educated people may have better information. They may, for instance, be able to secure less risky routes, or have better contacts to administrations. ${ }^{14}$

The budget constraint is another element that is important for our understanding of irregular migration. Costs of migration are high, they are often debt-financed, and migrants must pay part of the costs upfront. Hence, wealth $\mathrm{W}$ must be larger or equal the costs of migration. We assume that the costs of migration are proportional to the distance $D$ by a factor $s$, and that a proportion $k$ of these monetary costs must be paid upfront. The monetary costs may or may not include a profit component. Importantly, the costs that are relevant for the budget constraints are the monetary costs only, and we assume that these are proportional to the distance travelled.

Predictions: In this framework, the following predictions follow in a straightforward way: migration intentions should be, ceteris paribus, higher for people (i) with higher education, (ii) from households with more members in working age, and less dependent members, (ii) with networks abroad, (iv) who have more wealth and can hence pay the down payment needed. We should also expect people who are dissatisfied with their living conditions to be more likely to migrate (following from a reinterpretation of $B_{o}$ ).

\footnotetext{
${ }^{13}$ Note that we fully abstract from very-high skilled people, i.e. those with a human capital which is fully valuable also in destination countries, for two main reasons. First, they are irrelevant in the empirical analysis, so any findings about them is likely to be not statistically significant. Second, they are more likely to migrate legally, and the determinants driving such choice are fully controlled by our large set of fixed effects.

${ }^{14}$ Note also that we have included all the foregone benefits and opportunity costs associated with migration in the first term of the objective function, and hence do not account for them here.
} 
Predictions about the effect of a decrease in distance $D$ are a bit more involved but still unambiguous. The net benefit of migration increases, because the physical cost of migration decreases. Furthermore, the budget constraint is relaxed. Consequently, migration intentions should increase in general.

In terms of interactions between a decrease in $D$ and personal characteristics, we have no a priori knowledge about the sign of the cross-derivatives of $c$ with respect to personal characteristics. However, there is an unambiguous effect through the budget constraint. When $D$ decreases, the level of wealth needed to pay the upfront costs of migration decreases, which should lead to an increase of relatively less wealthy people's migration intentions. Wealth is often badly measured in developing economies, while education is a good proxy for wealth. Through the relaxed budget constraint, the decrease in $D$ should hence increase the intentions to migrate of less educated people. There is however a countervailing effect if the cross derivative of $c$ with respect to $D$ and $H$ were negative. In this case there is no clear prediction on how $D$ and education should interact. Hence, interaction effects between personal characteristics and the reduction in $D$ remain an empirical question we turn to in the next section.

\section{Data}

We use information on potential migrants from two waves of the Gallup's World Poll (GWP) which is a repeated cross-section, nationally representative individual-level dataset covering more than 150 countries over several years. ${ }^{15}$ GWP builds on yearly surveys of residents older than 15 years of age in more than 150 countries and represents more than 98 per cent of the world's adult population (e.g. see (Docquier et al., 2014), (Dustmann and Okatenko, 2014) or (Manchin and Orazbayev, 2016) for papers using the same dataset). ${ }^{16}$ While the GWP contains data from 2005 onwards, we limit our sample to years 2010 and 2012, excluding year 2011 because of the Arab Spring and the associated spike in migration across the Mediterranean sea. The reason for not using other years from the survey is that we do not want confounding factors to bias our analysis. Indeed, before and after the period we consider, other bilateral and multilateral (EU) agreements or migrationpolicy measures have been put in place systematically, also due to the change of environment we are considering, i.e. the opening of the CMR and the booming of irregular flows (e.g. The Mare Nostrum Operation was launched in 2013). We limit our sample to South-North migration to Europe so that we end up having 39 migrant-origin countries in Africa and the Middle-East, and

\footnotetext{
${ }^{15}$ The survey covers each country comprehensively, including rural areas. See further details on the dataset and a full list of available variables in Esipova et al. (2011) and Gallup (2012).

${ }^{16}$ The information is collected from randomly selected, nationally-representative samples of about one thousand individuals per country. In some countries, larger samples are collected in major cities or areas of special interest. Additionally, in some large countries, such as China and Russia, sample sizes increase to at least two thousand respondents. The survey covers each country comprehensively, including rural areas, with the country samples being probability based (i.e. the weights applied in the survey are used in the empirical analysis of this paper).
} 
29 European destination countries for two time periods, in a pre-post fashion. We exclude from our estimation sample Libya as this country is affected by both the opening up of the CMR and the demise of the Migration Treaty with Italy, which may constitute a country-specific bilateral shock. We further exclude its neighbouring countries, Tunisia and Egypt, for the same reasons we exclude Libya and also because right in 2011 they experienced an internal revolution which led to radically different governmental settings that in turn may generate bilateral-specific shocks. ${ }^{17}$

By its clandestine nature, irregular migration is not observable and it is empirically difficult to account for its size and composition. An advantage of using intentions to migrate instead of actual migration is that intentions are likely to be a primary determinant of the supply side of international migration flows. Indeed, intentions provide a measure of migration propensities also including potential illegal migrants, which are omitted from most migration statistics. On the other hand, a common concern when using intentions is whether intentions are "mere words or true plans" (van Dalen and Henkens, 2008). Other studies have been conducted using migration intentions from GWP show that there is a high correlation of cross-country data on intentions with actual migration flows (see for example (Docquier et al., 2014)). In this paper, we use a rather strict definition of migration intentions by considering positive answers to the three GWP questions altogether, i.e. whether respondents would like to move abroad and whether they are likely or they plan to do so in the following year. ${ }^{18}$

Key to our study, after answering the individual intention to migrate, GWP survey asks respondents to indicate a preferred country of destination, which allows us to investigate migration intentions by origin-destination pairs and merge them with both origin and destination countryspecific data. We focus on the area across the Mediterranean sea (i.e. Africa, Middle East and Europe) so that our final dataset consist of micro-level information from individuals living in about 30 developing countries, reporting 29 European countries as preferred destination, in the years 2010 and 2012 .

In order to check to what extent our variable on international migration intention can be a proxy for actual migration, we merged our data with two different datasets containing actual migration. Since these datasets are at aggregate level (country-level instead of individual-level), we aggregated our data using actual population data and survey weights. First, we used bilateral migration flows

\footnotetext{
${ }^{17}$ Ultimately, our sample of origin countries include Marocco, Algeria, Benin, Burkina Faso, Botswana, Central African Republic, Cameroon, Congo (DR), Congo, Comoros, Djibouti, Gambia, Ghana, Guinea, Kenya, Liberia, Mali, Mauritania, Malawi, Niger, Nigeria, Rwanda, Sudan, Senegal, Sierra Leone, Somalia, Chad, Tanzania, Uganda, South Africa, Zambia, Zimbabwe, Iraq, Israel, Jordan, Lebanon, Syria, Yemen. Among destination countries, our sample includes Albania, Austria, Belgium, Bulgaria, Czech Republic, Croatia, Serbia, Switzerland, Denmark, Germany, Spain, Estonia, Hungary, Finland, France, Greece, Italy, UK, Ireland, Luxembourg, Latvia, Montenegro, Norway, Sweden, Poland, Romania, Netherlands, Slovenia, Turkey.

${ }^{18}$ Migration intention is measured by using the answer to the following questions: (i) "Ideally, if you had the opportunity, would you like to move permanently or temporarily to another country, or would you prefer to continue living in this country?"; (ii) In the next 12 months, are you likely or unlikely to move away from the city or area where you live?"; (iii) Are you planning to move permanently to another country in the next 12 months, or not?"; (iv) "To which country would you like to move?
} 
from OECD (these contain some missing country-pairs), second, we used bilateral migration stock from (Brücker et al., 2013). The migration stock data provide the number of migrants in the destination country originating from a given country based on census data for the years 1980-2010 for every five years. From this we calculated the yearly average net bilateral flows (by taking the difference between the stocks) and match this to our data. The correlation between our data on international migration intentions and the actual migration flows obtained from both datasets for 2010 is around $0.71-0.72$.

Table 1 reports average emigration rates based on migration intentions for our sample (i.e. aggregate migration intentions as a share of total population). On average, migration intentions increase from 0.71 percent of the population in 2010 to 0.88 percent in 2012. In our sample, migration intentions are mainly concentrated in the youth and male population. Indeed, the share of males in total population with migration intentions was $0.43 \%$ in 2010 ( $0.29 \%$ for females), which increased to $0.59 \%$ in 2012 . Similarly to males, the share of young people with migration intentions in total population also increased during the period. Moreover, aggregate data reveal a decrease in migration intentions among low-skilled individuals (i.e. those with no more than primary education) which represent more than half of the total population of potential migrants. Instead, migration intentions increase among those with more skills (i.e. secondary education and above) with the share of high-skilled with migration intentions increaseing from $0.31 \%$ to $0.55 \%$.

Table 1: Emigration intention rates as \% of population (Gallup World Poll, 2010-2012)

\begin{tabular}{lcc}
\hline & 2010 & 2012 \\
\hline Emigration rate & 0.71 & 0.88 \\
Male emigration rate & 0.43 & 0.59 \\
Youth emigration rate $(<30)$ & 0.44 & 0.59 \\
Low-skilled emigration rate & 0.40 & 0.33 \\
High-skilled emigration rate & 0.31 & 0.55 \\
\hline
\end{tabular}

Note. Emigration rate is the population weighted average across our sample of country-level emigration rates (which are defined as the share of population with migration intentions). Low-skilled is defined as primary education, high-skilled is defined as secondary education and more.

Table 2 reports migration intentions for the top ten countries with highest emigration rates (based on intentions) with all these countries above the sample average. Table 3 provides further details on where people from the top five highest emigration countries would like to migrate, listing the two most important destinations for each country. The preferred destinations by country are only a few, with most respondents hoping to go to a few selected destination countries in Europe. 
Table 2: Migration shares- Top ten origin countries (GWP, 2010-2012)

\begin{tabular}{ccccc}
\hline Rank & \multicolumn{2}{c}{2010} & \multicolumn{2}{c}{2012} \\
\cline { 2 - 5 } & Origin country & Emigration rate & Origin country & Emigration rate \\
\hline 1 & Senegal & 6.58 & Comoros & 4.17 \\
2 & Djibouti & 3.78 & Sengal & 3.49 \\
3 & Comoros & 2.81 & Sudan & 2.33 \\
4 & Somalia & 2.12 & Ghana & 2.07 \\
5 & Mali & 1.98 & Guinea & 1.72 \\
6 & Mauritania & 1.45 & Algeria & 1.68 \\
7 & Morocco & 1.28 & Mauritania & 1.64 \\
8 & Sudan & 1.05 & Congo Rep. & 1.29 \\
9 & Ghana & 1.02 & Morocco & 1.29 \\
10 & Algeria & 0.87 & Nigeria & 1.18 \\
\hline
\end{tabular}

Table 3: Bilateral migration shares- Top-five origin countries with top-two destinations (Gallup World Poll, 2010-2012)

\begin{tabular}{|c|c|c|c|c|c|c|}
\hline \multirow[t]{2}{*}{ Rank } & \multicolumn{3}{|c|}{2010} & \multicolumn{3}{|c|}{2012} \\
\hline & Origin & Top-2 destination & Emigration rate & Origin & Top-2 destination & Emigration rate \\
\hline \multirow{2}{*}{1} & \multirow{2}{*}{ Senegal } & Spain & 2.36 & \multirow{2}{*}{ Comoros } & France & 3.99 \\
\hline & & Italy & 1.86 & & Germany & 0.177 \\
\hline \multirow{2}{*}{2} & \multirow{2}{*}{ Djibouti } & France & 2.39 & \multirow{2}{*}{ Senegal } & France & 1.44 \\
\hline & & UK & 0.48 & & Spain & 1.30 \\
\hline \multirow{2}{*}{3} & \multirow{2}{*}{ Comoros } & France & 2.48 & \multirow{2}{*}{ Sudan } & UK & 1.25 \\
\hline & & UK & 0.14 & & France & 0.58 \\
\hline \multirow{2}{*}{4} & \multirow{2}{*}{ Somalia } & UK & 1.42 & \multirow{2}{*}{ Ghana } & UK & 1.20 \\
\hline & & Sweden & 0.25 & & Spain & 0.60 \\
\hline \multirow{2}{*}{5} & \multirow{2}{*}{ Mali } & France & 0.82 & \multirow{2}{*}{ Guinea } & France & 0.76 \\
\hline & & Spain & 0.60 & & UK & 0.43 \\
\hline
\end{tabular}

\subsection{Bilateral Distance}

We construct a matrix of bilateral distances from each country of origin $(o)$ to each destination (d) by mapping migration routes between Africa, Middle East and Europe. Unlike air distance, migration routes change over time, hence we construct the matrix $D_{\text {odt }}$ where $t$ is year 2010 and 2012. ${ }^{19}$ The assembling process follows several steps. First, the patterns of international migration routes from less developed countries to developed (European) countries have been geolocalized from the maps provided by the iMap website ${ }^{20}$, which has been developed by ICMPD, Europol and Frontex jointly. Each country is represented by the coordinates of its capital city, as the migration routes usually go through it and because the location of the capital city is often a good proxy for the center of mass of each country in terms of population. The structure of migration routes

\footnotetext{
${ }^{19}$ We constructed a full matrix for each African and European country pair but the coverage in the GWP defines the number of country pairs used in the regression analysis.

${ }^{20}$ http://www.imap-migration.org/
} 
represent the network connecting all of the countries in our sample ${ }^{21}$

In Figure 4 the network of migration routes in 2010 is represented by the red segments connecting the (capitals of) African and European countries. The blue segments represent the sea routes that after the Arab Spring, and in particular after the end of the Gaddafi's regime, became available again since the end of 2011. Hence, the CMR has been added to the 2010 network to obtain the new structure as of 2012 .

Figure 4: Network of migration routes

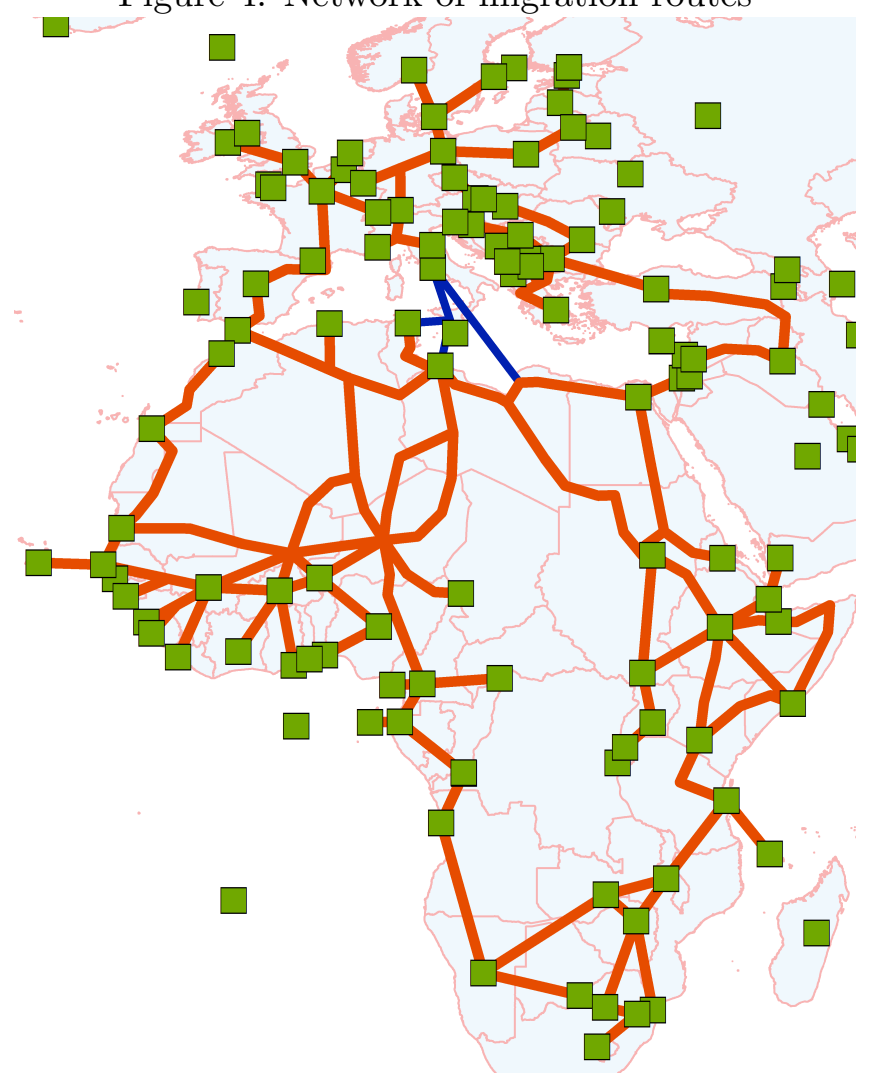

Notes: The figure shows the location of the capital cities of countries (squares) and the migration routes connecting them (lines). Countries not connected are excluded from the sample. Red migration routes relative to year 2010 are obtained from iMap website, while blue ones are those added to construct the network in 2012.

The distance associated with each origin-destination pair is the minimal geodesic distance calculated by means of a Djkstra algorithm along the segments of the network. ${ }^{22}$ In order to avoid too much arbitrariness, we do not impose differential transit costs depending on altitude, ruggedness or other geomorphological characteristics, so the cost of moving between nodes maps one to one with the distance 23 .

\footnotetext{
${ }^{21}$ Those off the migration routes have been connected to their closest neighbouring country using the shortest straight link.

${ }^{22}$ The implicit assumption here is that the cost of connecting two nodes off the migration routes is infinite.

${ }^{23}$ We obtain almost identical results by recoding sea routes being one fifth cheaper than land routes, i.e. rescaling the length of segments across sea by a factor of 0.2 . The fact that this modification has little effect on the results can be rationalized as, first, the length of the average route connecting a country pair is in the order of magnitude of thousands of kilometers and the maximum sea distance (between Libia and Italy) is of less then 300 kilometers.
} 
The resulting matrix can be represented in Figure 5, where each dot is an origin-destination country pair and the axes report the distance along smuggling routes in 2010 and 2012. It is worth noting that, by construction, the addition of links in the network (the CMR opened in 2011) made the minimal distance between country pairs either unchanged or shorter, particularly for those country-pairs close to the new links. Note that the lower the dots from the 45-degree line, the closer the country pairs get between year 2010 and 2012. Some country-pairs have been labelled as examples, such as Morocco-Spain (the closest pair, which however does not change its bilateral distance over time), Jordan-Italy (the pair experiencing the largest reduction in distance), YemenSweden (a pair made of very distant countries which experienced a sizeable reduction in distance, more than 2000 kilometers).

In Figure 6 we plot how the drop in distance between year 2010 and 2012 is distributed at given absolute distances (in 2010), showing that large drops are not only concentrated among those country pairs already close to each other. Finally, Figure 7 shows that there is a sizeable amount of country pairs for which distance dropped between 2010 and 2012.

Figure 5: Distance between pairs of countries

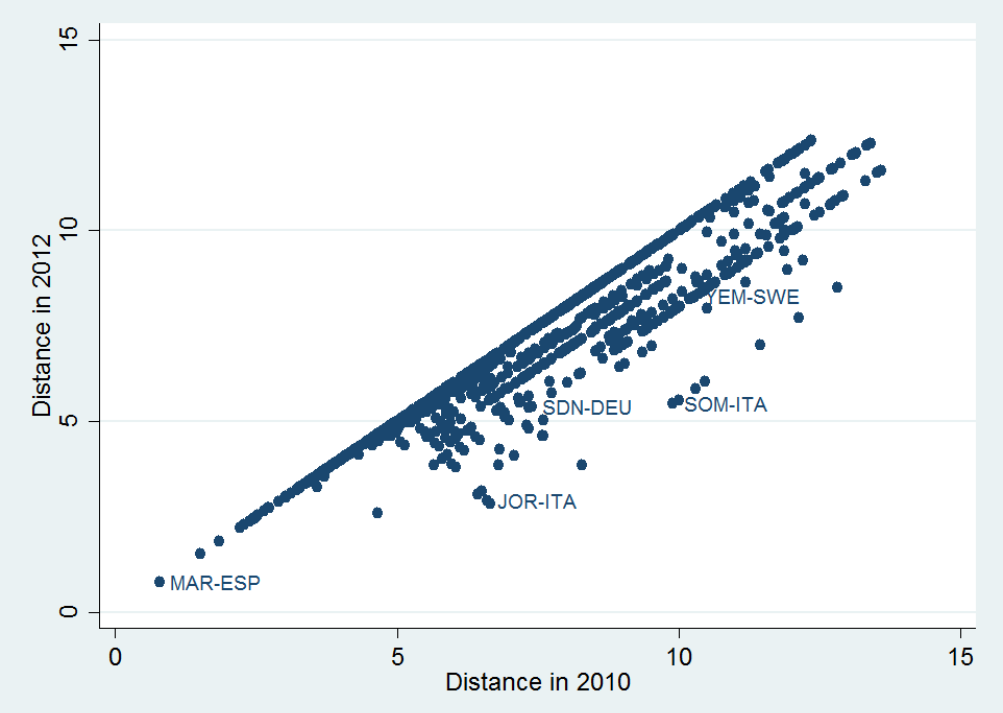

Notes: The figure shows the distances, in 1,000 Kilometres, between country pairs in 2010 and 2012 .

\section{Descriptive analysis of aggregate irregular flows}

Before turning to our main results on bilateral intentions to migrate, we further use Frontex data on migrant flows arriving at European borders in order to assess whether the opening of the CMR

Second, the important change between distances across the two periods is the emergence of central Mediterranean route, with its length playing a minor role in the overall change. It is therefore the possibility of finding shorter paths across the network (by means of additional nodes) rather than the shortening of existing segments that mostly contribute to the variation in distances across the two periods. 
Figure 6: Distance between pairs of countries and its reduction

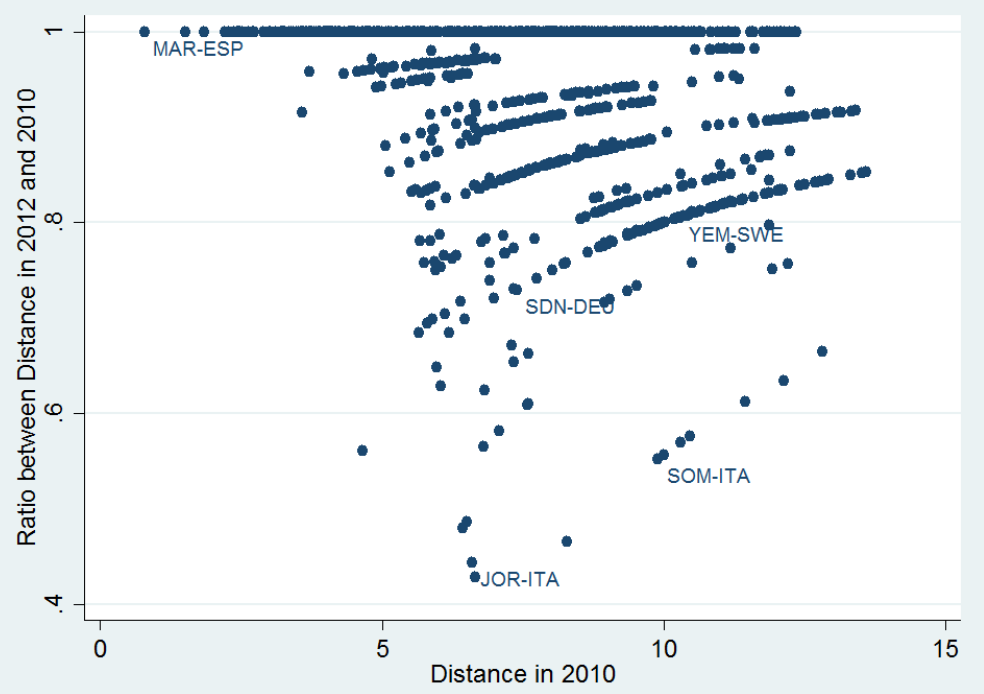

Notes: The figure shows, for each country pair, the ratio between distance in 2012 and 2010 against the distance in 2010 , in 1,000 Kilometres.

Figure 7: Distance among country pairs and its reduction

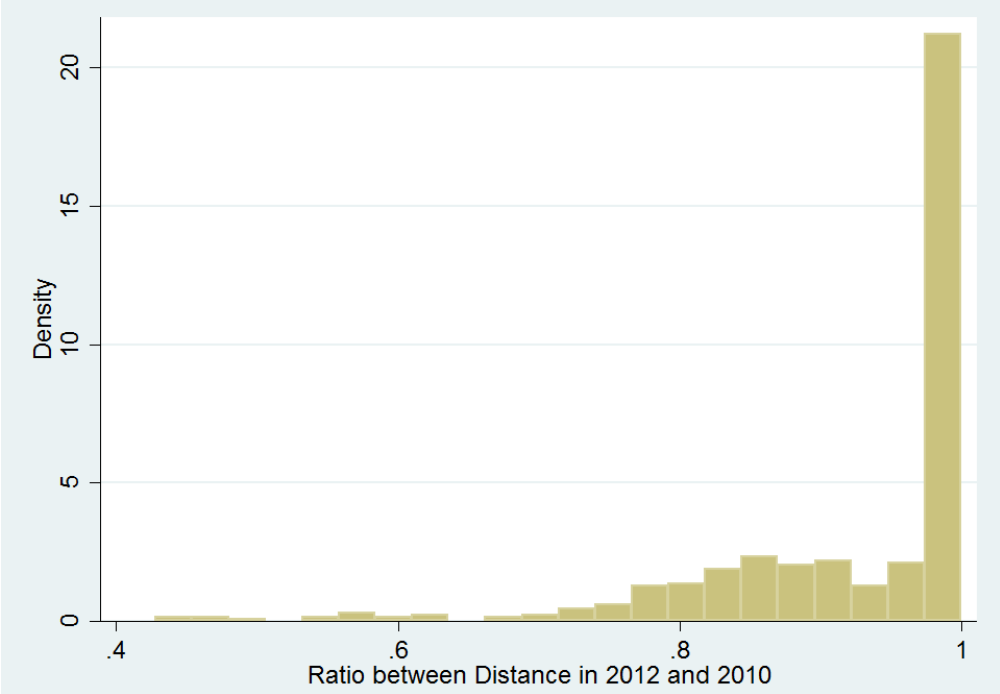

Notes: The figure shows the distribution, calculated among country pairs, of the ratio between distance in 2012 and 2010.

was coupled with any other major change in the region during the same period of time. This is important in order to rule out a general equilibrium effect whereby the direct effect of the CMR shock is offset by potential migrant relocation along other routes. ${ }^{24}$ To do so, we assemble monthly data of arrivals of immigrants collected by Frontex, which classifies individuals in terms of (selfdeclared) nationality and hub of arrival, the classification of routes being the same proposed in Figure 3. Data is organized therefore as a panel of monthly country-level flows arriving in Europe

\footnotetext{
${ }^{24}$ This general equilibrium effect is mechanically muted in our empirical model, as outlined in the following section.
} 
either through the CMR or any other routes. By using our smuggling distance matrix, we estimate migration flows as a function of a treatment dummy, which is equal to one if the country experienced a drop in distance from at least one European destination country for the months after December 2011. Figure 8 shows that some countries (such as Benin, Malawi, or Zambia) did not experience any drop in distance, while others (such as Botswana, Chad or Somalia) got closer to many of the destination countries. ${ }^{25}$ The empirical specification therefore is as follows:

$$
M_{o t}^{R}=\gamma_{1} T_{o t}+\delta_{o}+\tau_{t}+\epsilon_{o t}
$$

where $M_{o t}^{R}$ is the number of immigrants from country $o$ arriving to Europe in month $t$ using the smuggling route $R$, which can be either the CMR or any other route. $T_{o t}$ is our treatment variable, which is equal to one since January 2012 for those countries $o$ that get closer to at least one European destination country, $\delta_{o}$ are country fixed effects (or a dummy for the treated countries) and $\tau$ are month fixed effects or simply the usual pre-post dummy. $\epsilon_{o t}$ is an i.i.d. error term.

Figure 8: Distribution of the drop in smuggling distance

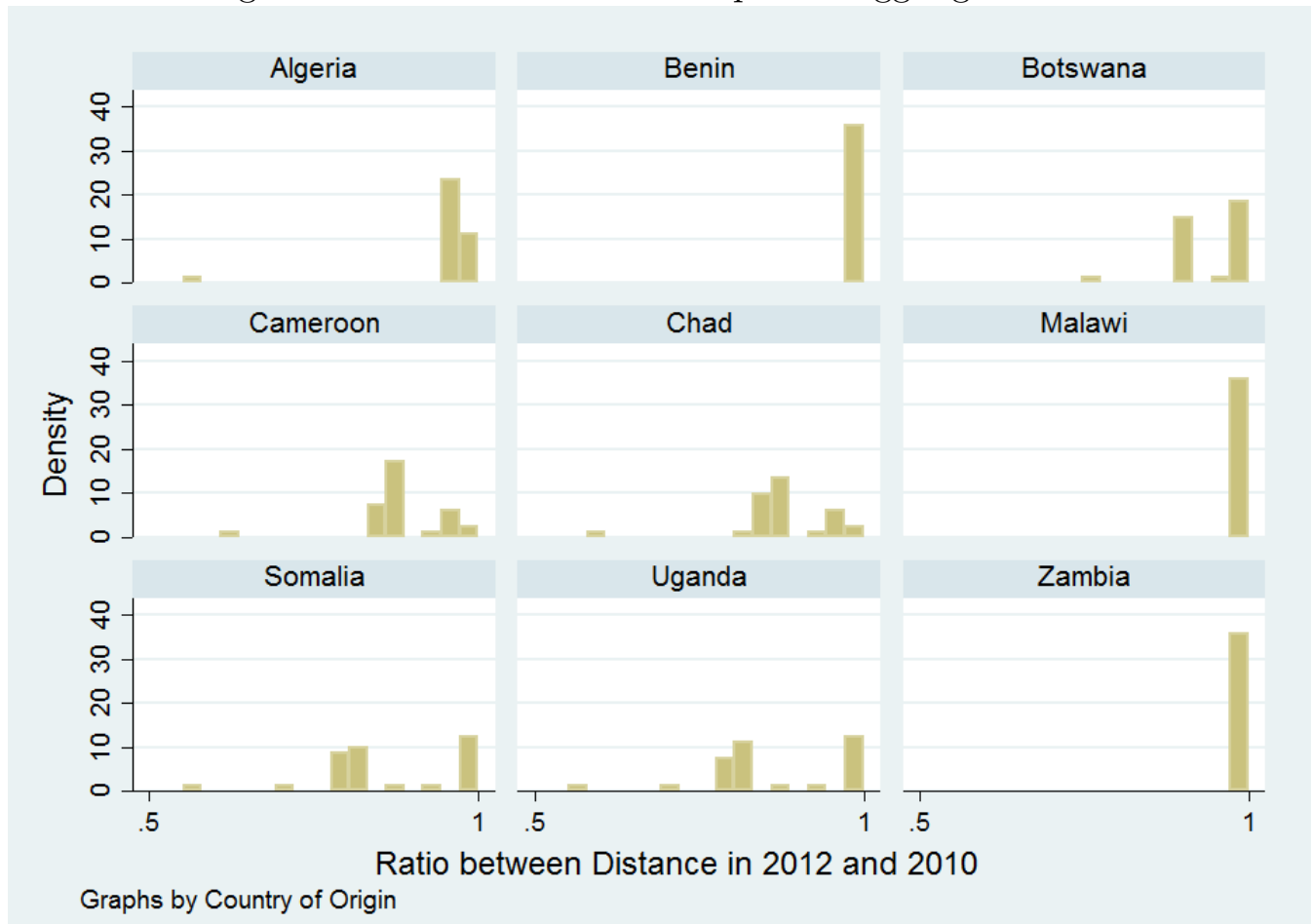

Notes: The figure plots the distribution of the drop in smuggling distance from all European countries between year 2010 and 2012 by selected country of origin. Source: Frontex.

Results presented in the first three columns of Table 4 show that the opening of the CMR boosted irregular flows (arrivals) even after controlling for the lagged flow of migrants that take into account short-term network effects (see second row). Importantly, once we use the flows of

\footnotetext{
${ }^{25}$ Figure 8 shows only selected countries to improve readability.
} 
Table 4: The impact of CMR opening on monthly arrivals in Europe

\begin{tabular}{|c|c|c|c|c|c|c|}
\hline \multirow{2}{*}{$\begin{array}{l}\text { Dependent Variable } \\
\gamma_{1}\end{array}$} & (1) & $(2)$ & \multirow{2}{*}{$\mathrm{MR}^{(3)}$} & $(4)$ & $(5)$ & \multirow{2}{*}{$\begin{array}{c}(6) \\
\text { ler routes }\end{array}$} \\
\hline & Migr: & nts through $\mathrm{C}$ & & Migrant & through of & \\
\hline$\gamma_{1}$ & $\begin{array}{c}14.3542^{* * *} \\
{[3.6010]}\end{array}$ & $\begin{array}{c}14.3542^{* * *} \\
{[3.6501]}\end{array}$ & $\begin{array}{c}9.2879 * * * \\
{[3.1716]} \\
0.3688^{* *} \\
{[0.1698]}\end{array}$ & $\begin{array}{c}-0.1319 \\
{[12.9292]}\end{array}$ & $\begin{array}{c}-0.1319 \\
{[13.0729]}\end{array}$ & $\begin{array}{c}-1.7470 \\
{[9.4965]} \\
0.6943 * * * \\
{[0.1468]}\end{array}$ \\
\hline Observations & 864 & 864 & 864 & 864 & 864 & 864 \\
\hline Country FE & YES & YES & YES & YES & YES & YES \\
\hline Post 2011 dummy & YES & NO & NO & YES & NO & NO \\
\hline Month FE & NO & YES & YES & NO & YES & YES \\
\hline
\end{tabular}

Notes: The dependent variable is the monthly flow of migrants arriving in Europe using the CMR (columns 1 to 3 ) or any other routes (columns 4 to 6 ). The estimation sample is the 12 months of year 2010 and the 12 months of year 2012 . Results are estimated by means of OLS. All regressions include a set of country fixed effects and a dummy for months in year 2012 (columns 1 and 4) or monthly dummies (other columns). Columns 3 and 6 include the one month lag of the dependent variable. Robust standard errors are reported in brackets. ${ }^{* * *} \mathrm{p}<0.01,{ }^{* *} \mathrm{p}<0.05,{ }^{*} \mathrm{p}<0.1$

migrants arriving through any other route, results on the coefficient of the treatment are small, negative and non-significant, implying that no diversion of flows has been put in place by the opening of the CMR. This puts us on the safe side once we implement the empirical specification presented in the next section. ${ }^{26}$

\section{The impact of smuggling distance on individual migration in- tentions: Empirical Strategy}

In our empirical specification we use a gravity-like specification. The gravity model has been extensively used to empirically model trade flows since Tinbergen (1962), and the theoretical foundations have been linked to different trade models (see an overview in Head (2014)). In addition, the gravity model has been also applied to other type of flows between countries, including migration flows. ${ }^{27}$ We employ the gravity framework and exploit an exogenous shock to distance in migration routes to estimate the impact of the latter on individual-level migration intentions to country-specific destinations. Hence, the bilateral estimation equation is as follows:

$$
M_{i o d t}=\beta_{0}+\beta_{1} X_{i o t}+\beta_{2} \ln \mathbf{D}_{o d t}+v_{o t}+w_{d t}+u_{o d}+e_{i o d t}
$$

where the outcome variable $M_{i o d t}$ is a binary indicator of migration intention of individual $i$ to move from country of origin $o$ to country of destination $d$ at time $t$. The regressor of interest, $\ln D_{\text {odt }}$ is the time-varying (log of) distance, measuring the distance between the origin and destination

\footnotetext{
${ }^{26}$ Results hold even expanding the sample to months of years 2009 and 2013 and including year 2011 among the non-treated. Also, by using a stricter definition of treatment (i.e. countries that got closer to at least two destinations) results remain unchanged.

${ }^{27}$ Beine et al. (2015) provide a good overview of the gravity model's application to international migration flows laying out also the theoretical basis
} 
country along migration routes. In addition, we control for a vector of individual covariates, $X_{i o t}$, which include age, gender, education, household size, wealth, urban city residence, satisfaction with local amenities. ${ }^{28}$ Finally, we also include country-pair fixed effects $\left(u_{o d}\right)$ together with a full set of origin-by-year $\left(v_{o t}\right)$ and destination-by-year $\left(w_{d t}\right)$ fixed effects. ${ }^{29}$ The latter control for all static and dynamic standard socio-economic pull and push drivers of migration, including economic incentives at origin and migration policy at destination. The inclusion of country-pair fixed effects controls for any bilateral determinants of location choices such as geographical and economic proximity, common language, shared tastes and bilateral migration policy. ${ }^{30}$ Hence, the identification comes from short-run changes - in particular a reduction - in the length of irregular migration routes, which translate into changes in smuggling services supply. Throughout, estimates allow for arbitrary correlation across both orgin and destination countries so that standard errors are two-way clustered. In particular, since we have individual observations which may be correlated (e.g. subject to the same shocks) within the home country (push factors) and the country pair (bilateral factors), we present robust results under within groups correlated errors. ${ }^{31}$

We further explore heterogeneity in the distance effect. In particular, in the spirit of a differencesin-differences strategy, we exploit time-invariant (air) distance from Libya to investigate treatment intensity effects. Indeed, living closer to Libya may entail higher marginal utility from the opening of CMR than it is the case for those living further away. This is so as, in the absence of CMR, those living close to Libya and willing to migrate irregularly to the EU should travel through longer migration routes in order to reach alternative hubs (e.g. western or eastern mediterranean routes). Hence, in additional specifications we exploit both time variation in smuggling distance (as above) and geographical variation across countries - in particular air distance from Libya (i.e. intensity of the treatment).

Finally, by estimating equation (1) we are able to uncover the average causal effect of access to shorter illegal migration routes on the individual-level intention to migrate. Hence, we investigate heterogeneous effects of the human smuggling shock by interacting our measure of availability of human smuggling services (proxied by the time-varying migration distance) with individual-level characteristics. This allows us to uncover the features of individuals who respond more (or less) to the incentive for irregular border crossings. In particular, since international migration is a high

\footnotetext{
${ }^{28}$ Since recent empirical evidence shows that income considerations are not the only factor influencing migration decisions, our analysis also incorporates non-economic factors. In particular, we control for individuals overall contentment with own living standards and local amenities such as public services, security, or governance (see for example (Dustmann and Okatenko, 2014) or (Manchin and Orazbayev, 2016)).

${ }^{29}$ A similar empirical strategy has been used in Pascali (2017), that uses a time-varying (measure of) distance as explanatory variable in a standard gravity trade model.

${ }^{30}$ Given that our time-frame is short, very little change (if any) would have taken place over the period in terms of bilateral migration policies.

${ }^{31}$ More specifically, we use two-way clustered standard errors since we are interested in generalizing results to the whole population in the origin country willing to migrate across all possible country-pairs, beyond those in the sample (see Abadie et al.2017).
} 
risk and costly process (even more along the central Mediterranean route), we interact our distance measure with individual level characteristics which proxy for differentials in (time-equivalent) migration costs, such as gender, age, education and social networks. Results on interaction effects help confirming identification since any potential aggregate omitted variables would have to behave differently across sub-groups in order to exhibit the sorts of heterogeneous effects we find.

\section{Results}

We start by estimating the impact of changes in migration route distance on individual migration intentions, as specified in equation (2), controlling for individual-level characteristics, country-bytime and pair fixed effects. The latter sweeps out all (observable and unobservable) heterogeneity at the level of country of origin, destination and pair. In particular, they include air distance and time-invariant (between 2010-2012) common factors such as bilateral (visa) agreements, countries' proximity in terms of language, culture and living standards. Origin- and destination-country-bytime fixed effects control for static and dynamic push and pull factors of international migration at the country-level such as (origin and destination) GDP, wages, conflicts, climate shocks and migration policy. Finally, individual characteristics include a vector of controls typically affecting the migration decision including age, gender, marital status, family size (number of children), wealth indicators (two principal component indexes), a dummy for having a family member/friend abroad (migration network), a dummy for urban (city) area, and satisfaction for amenities. As for the wealth index, we use a principal component analysis based on ten survey questions including household income by quintiles, individual perception/satisfaction with income and standards of living, expectations about future standard of living, and assets ownership. ${ }^{32}$ We retain the first two components, which jointly explain $59 \%$ of the underlying variation. While the first component, which we call 'wealth', mostly captures actual income and wealth, the second component, which we refer to as 'standard of living', is about the current, and more importantly expected standard of living.

Table 5 reports estimates with a linear probability model of the impact of distance on bilateral migration intentions. As not to impose a specific functional form for the distance effect, we use a

\footnotetext{
${ }^{32}$ By exploiting the unique richness of WGP, in order to measure wealth we include the following survey questions in the pricipal component analysis: Income quintile (household income within country quintiles); Perception of present income (Which one of these phrases comes closest to your own feelings about your household income these days?); Current standard of living (Are you satisfied or dissatisfied with your standard of living, all the things you can buy and do?); Changes in standard of living (Right now, do you feel your standard of living is getting better or getting worse?); Mobile phone at home (Does your home have a cellular phone?); Television at home (Does your home have a television); Internet access at home (Does your home have access to the Internet?); Money for food (Have there been times in the past 12 months when you did not have enough money to buy food that you or your family needed?); Money for shelter (Have there been times in the past 12 months when you did not have enough money to provide adequate shelter or housing for you and your family? Since many variables are binary, the analysis is done using polychoric principal component (see Kolenikov and Angeles, 2004). Yet, as a robustness check, we also run standard principal component analysis and results are not affected.
} 
logarithmic, linear and non-linear (quartile dummies) specification of the distance variable (reported in column (1), (2) and (3) respectively). Throughout, standard errors are two-way clustered at the level of country of origin and country-pair.

Table 5: The impact of distance on bilateral migration intentions

\begin{tabular}{|c|c|c|c|}
\hline & $(1)$ & $(2)$ & $(3)$ \\
\hline Log smuggling distance & $\begin{array}{c}-0.0049^{*} \\
{[0.0027]}\end{array}$ & & \\
\hline Linear smuggling distance & & $\begin{array}{c}-0.0004^{*} \\
{[0.0002]}\end{array}$ & \\
\hline First quartile dummy & & & $\begin{array}{c}0.0031^{* *} \\
{[0.0015]}\end{array}$ \\
\hline Second quartile dummy & & & $\begin{array}{c}0.0014 \\
{[0.0010]}\end{array}$ \\
\hline Third quartile dummy & & & $\begin{array}{c}0.0010 \\
{[0.0008]}\end{array}$ \\
\hline Female & $\begin{array}{l}-0.0001 \\
{[0.0001]}\end{array}$ & $\begin{array}{l}-0.0001 \\
{[0.0001]}\end{array}$ & $\begin{array}{l}-0.0001 \\
{[0.0001]}\end{array}$ \\
\hline Age & $\begin{array}{c}-0.0000^{* *} \\
{[0.0000]}\end{array}$ & $\begin{array}{c}-0.0000^{* *} \\
{[0.0000]}\end{array}$ & $\begin{array}{c}-0.0000^{* *} \\
{[0.0000]}\end{array}$ \\
\hline Married & $\begin{array}{c}-0.0001^{* * * *} \\
{[0.0000]}\end{array}$ & $\begin{array}{c}-0.0001^{* * *} \\
{[0.0000]}\end{array}$ & $\begin{array}{c}-0.0001^{* * *} \\
{[0.0000]}\end{array}$ \\
\hline Primary Education & $\begin{array}{c}0.0000 \\
{[0.0001]}\end{array}$ & $\begin{array}{c}0.0000 \\
{[0.0001]}\end{array}$ & $\begin{array}{c}0.0000 \\
{[0.0001]}\end{array}$ \\
\hline Household size & $\begin{array}{c}0.0000 \\
{[0.0000]}\end{array}$ & $\begin{array}{c}0.0000 \\
{[0.0000]}\end{array}$ & $\begin{array}{c}0.0000 \\
{[0.0000]}\end{array}$ \\
\hline Close networks abroad & $\begin{array}{c}0.0004^{* * *} \\
{[0.0001]}\end{array}$ & $\begin{array}{c}0.0004^{* * *} \\
{[0.0001]}\end{array}$ & $\begin{array}{c}0.0004^{* * *} \\
{[0.0001]}\end{array}$ \\
\hline Wealth & $\begin{array}{l}0.0002^{*} \\
{[0.0001]}\end{array}$ & $\begin{array}{l}0.0002^{*} \\
{[0.0001]}\end{array}$ & $\begin{array}{l}0.0002^{*} \\
{[0.0001]}\end{array}$ \\
\hline Standard of living & $\begin{array}{c}-0.0005^{* * *} \\
{[0.0002]}\end{array}$ & $\begin{array}{c}-0.0005^{* * *} \\
{[0.0002]}\end{array}$ & $\begin{array}{c}-0.0005^{* * *} \\
{[0.0002]}\end{array}$ \\
\hline Large city & $\begin{array}{c}0.0002 \\
{[0.0002]}\end{array}$ & $\begin{array}{c}0.0002 \\
{[0.0002]}\end{array}$ & $\begin{array}{c}0.0002 \\
{[0.0002]}\end{array}$ \\
\hline Satisfaction with the city/area & $\begin{array}{c}-0.0002^{* * *} \\
{[0.0001]}\end{array}$ & $\begin{array}{c}-0.0002^{* * *} \\
{[0.0001]}\end{array}$ & $\begin{array}{c}-0.0002^{* * *} \\
{[0.0001]}\end{array}$ \\
\hline Observations & $1,217,159$ & $1,217,159$ & $1,217,159$ \\
\hline OriginX2012 FE & Yes & Yes & Yes \\
\hline DestinationX2012 FE & Yes & Yes & Yes \\
\hline Pair FE & Yes & Yes & Yes \\
\hline
\end{tabular}

Notes: The dependent variable is a binary indicator for positive bilateral migration intention. Results are estimated with a linear probability model. All regressions include a set of individual-level controls plus country-pair and country-year fixed effects. Standard errors clustered at the level of origin country and country-pair are reported in brackets. $* * * \mathrm{p}<0.01, * *$ $\mathrm{p}<0.05, * \mathrm{p}<0.1$

Results show a significant negative effect of the change in distance along illegal migration routes between country pairs on the individual intention to migrate bilaterally. The log-linear specification shows that a 10 percent decrease in migration distance increases the probability to be willing to migrate to a specific destination by almost 0.05 percentage points (p.p.), which represents more than a doubling of the sample mean bilateral migration intentions rate (0.03 percent). According to the linear specification, a decrease in distance of $1000 \mathrm{Km}$ (2500 Km, one standard deviation) 
increases the likelihood to migrate by about $12 \%(30 \%)$ at the sample mean. Finally, in the last column of the table we report results with a quartile-dummy specification of the distance variable, where the fourth quantile is the reference category. Results show that a drop in distance which makes an individual ending up being in the first quartile of the distance distribution significantly increases migration intentions by about $10 \%$ at the sample mean. Changes that entails longer distance (higher quartiles) are still positively associated to migration intentions but less precisely estimated.

These findings are robust to the inclusion of individual controls as well as all fixed effects. Results on the individual level determinants of international migration intentions show the expected sign. In particular, young and married individuals are less likely to be willing to migrate, whereas being low-skilled (i.e. having no more than primary education) does not play a significant role in the migration decision. On the other hand, ceteris paribus, being better off in terms of wealth (and worse off in terms of expected living standards), living in a big city and having a network abroad (i.e. a friend or relative already migrated abroad) significantly increase migration intentions.

\subsection{The distance effect on migration intentions across countries}

In order to futher explore the elasticity of migration intentions across countries, we test the distance effect while grouping either origin or destination countries in different ways. First, we do so along an absolute geographical dimension, namely East vs West Africa and North vs Sub-Saharan Africa (SSA). Indeed, the opportunity cost (in terms of using alternative routes) of crossing Mediterranean through CMR may be different according to the individual's country of residence. Moreover, we exploit cross-country variation in air (time-invariant) distance from Libya to test whether people living in 'more intensively treated countries' (i.e. those closer to Libya) react more to the distance shock than individuals living further away. Indeed, if the CMR was closed, people living relatively close to Libya should travel much longer to reach the EU than their peers from other countries. Finally, in order to explore whether country-level characteristics do also play a role, we focus on whether the illegal nature of migration is associated with country-specific legal enforcement or rule of law. Hence, we allow for differential effects of smuggling distance between (origin and destination) countries with low vs high levels of rule of law.

Results reported in Table 6 show that people living in East vs West Africa are not differentially affected by the distance shock (column 1). People living in Southern Africa, instead, are less sensitive to the shock than people living in the Northern area (column 2). ${ }^{33}$ In order to explore this further, in column 3 we interact our smuggling distance measure with a dummy variable for

\footnotetext{
${ }^{33}$ In our Sub-Saharan dummy, Southern Africa includes Benin, Burkina Faso, Botswana, Central African Republic, Cameroon, Congo (DR), Congo, Comoros, Djibouti, Gambia, Ghana, Guinea, Kenya, Liberia, Malawi, Nigeria, Rwanda, Senegal, Sierra Leone, Somalia, Chad, Tanzania, Uganda, South Africa, Zambia, Zimbabwe. Northern Africa includes Morocco, Algeria, Mali, Mauritania, Niger, Sudan, Chad, Iraq, Israel, Jordan, Lebanon, Syria, Yemen.
} 
countries being above the median distance from Libya - posing that those residing in countries closer to Libya are more 'intensively treated' by the change in the smuggling distance. Results on the interaction term show that the elasticity to the smuggling shock is decreasing (in absolute terms) with distance from Libya, delivering an effect which is not statistically different from zero for those origin countries far away from Libya. The latter results are consistent with the non-linear effects presented in Table 5 above.

Finally, in column 4 we allow countries of origin below the median of the distribution of World Bank's index of rule of law to experience a differential effect of distance. ${ }^{34}$ In this case, the total effect of distance is negative and significantly different from zero only for individuals from country of origin with relatively low rule of law, suggesting that the smuggling industry running the business across the deserts could be more present in such types of countries.

Table 6: Heterogeneous distance effect across countries

\begin{tabular}{|c|c|c|c|c|}
\hline & $(1)$ & $(2)$ & $(3)$ & $(4)$ \\
\hline Log Smuggling distance & $\begin{array}{c}-0.0057^{* * *} \\
{[0.0016]}\end{array}$ & $\begin{array}{c}-0.0061^{* *} \\
{[0.0024]}\end{array}$ & $\begin{array}{c}-0.0059^{* *} \\
{[0.0029]}\end{array}$ & $\begin{array}{l}-0.0035 \\
{[0.0025]}\end{array}$ \\
\hline Log Smuggling distance ${ }^{*}$ East & $\begin{array}{c}0.0010 \\
{[0.0008]}\end{array}$ & & & \\
\hline Log Smuggling distance $*$ SSA & & $\begin{array}{c}0.0019 * * * \\
{[0.0007]}\end{array}$ & & \\
\hline Log Smuggling distance ${ }^{*}$ Far from Libya & & & $\begin{array}{c}0.0019^{* *} \\
{[0.0007]}\end{array}$ & \\
\hline Log Smuggling distance ${ }^{*}$ Low ROL origin & & & & $\begin{array}{c}-0.0022^{* *} \\
{[0.0008]}\end{array}$ \\
\hline Direct effect + Interacted term & $\begin{array}{l}-.0047^{*} \\
{[0.0024]}\end{array}$ & $\begin{array}{l}-0.0042 \\
{[0.0027]}\end{array}$ & $\begin{array}{l}-0.0040 \\
{[0.0024]}\end{array}$ & $\begin{array}{c}-0.0056^{* *} \\
{[0.0027]}\end{array}$ \\
\hline Observations & $1,217,159$ & $1,217,159$ & $1,217,159$ & $1,217,159$ \\
\hline Individual level controls & Yes & Yes & Yes & Yes \\
\hline OriginX2012 FE & Yes & Yes & Yes & Yes \\
\hline DestinationX2012 FE & Yes & Yes & Yes & Yes \\
\hline Pair FE & Yes & Yes & Yes & Yes \\
\hline
\end{tabular}

Notes: The dependent variable is a binary indicator for positertive bilater migration intention. Results are estimated with a linear probability model. All regressions include a set of individual-level controls plus country-pair and country-year fixed effects. Standard errors clustered at the level of origin country and country-pair are reported in brackets. ${ }^{* * *} \mathrm{p}<0.01, * *$ $\mathrm{p}<0.05,{ }^{*} \mathrm{p}<0.1$

\subsection{Heterogenous effects across sub-groups of individuals}

Here we investigate interacted effects in different sub-groups of the population, while controlling for unobserved heterogeneity through country-pair and country-by-time fixed effects. Results are presented in Table 7 where in the first column we report average estimates of the main regressors (we express some of the individual continuous controls above as binary variables). In the remaining columns we report estimates of the main regressors and interacted effects. Results are consistent in showing that a higher distance in migration routes decreases bilateral individual intention to

\footnotetext{
${ }^{34}$ The rule of law index comes from World Bank's Worldwide Governance Indicators for the year 2010.
} 
migrate. Yet, the effect is heterogeneous across sub-groups of the population. In particular, the negative effect of distance is not statistically different between men and women but it is bigger in absolute value for youth (i.e. individuals less than 35 years of age (col 3)) and more educated people (i.e. those with more than primary education, col 4). Moreover, while wealth-poor (i.e. those below the second quintile of the wealth distribution) and non-poor individuals are not differentially affected by the distance shock (col 5), those who expect to be poor in terms of living standard do respond more to the smuggling services supply shock (col 6). Finally, those with close social networks abroad (friends or relatives) are also more sensitive to the decrease in distance along CMR (last column). This is consistent with the argument that the opening of the CMR may not decrease migration monetary costs (as human smuggling is an expensive business) while it may require some skill and social networks (human capital).

In Table 8 we explore even further the compositional effect along the skill dimension by interacting the change in distance with two indicators of secondary and tertiary education respectively (with primary education as reference category). Results show that shorter distance along smuggling routes increases the willingness to migrate especially for individuals with secondary education rather than those with higher education and above. Indeed, the smuggling market is not without costs so that some skills are needed in order to be aware of migration opportunities and be able to afford them in time-equivalent terms.

\section{Conclusion}

In a world in which income disparities between north and south diverge, and the legal opportunities for migration become increasingly scarce, a global multi-billion USD human smuggling industry has arisen. Understanding (and where possible) predicting migration flows and their composition has become impossible without taking the role of the smuggling industry into account and trying to estimate the impact of the supply of human smuggling.

We merge geocoded data about smuggling routes and individual survey data on intentions to migrate into a gravity framework. Exploiting an exogenous shock that extended smuggling networks and hence shortened the distances between many country pairs, we provide estimates for the sensitivity of migration intentions to the supply of smuggling service. We also detect interesting heterogeneous responses. While there are no significant differences between females and males, the migration intention of young people and people with moderate education levels responds more intensively to the extention of the smuggling industry, and so do people with social ties to people who have already migrated.

To our knowledge, we are the first who use the natural experiment of the opening of the central mediterranean route in the course of the Arab spring and the demise of the Gaddafi regime, but the approach can be used for other important events as well, for instance the EU-Turkey 
Table 7: Heterogenous distance effects across individuals

\begin{tabular}{|c|c|c|c|c|c|c|c|}
\hline VARIABLES & $(1)$ & $(2)$ & $(3)$ & $(4)$ & $(5)$ & $(6)$ & (7) \\
\hline Female & {$[0.0001]$} & {$[0.0052]$} & {$[0.0001]$} & {$[0.0001]$} & {$[0.0001]$} & {$[0.0001]$} & {$[0.0001]$} \\
\hline \multirow[t]{2}{*}{ Youth $(<35)$} & $0.0002^{* * *}$ & $0.0002^{* * *}$ & $0.0065^{*}$ & $0.0002 * * *$ & $0.0002^{* * *}$ & $0.0002^{* * *}$ & $0.0002^{* * *}$ \\
\hline & {$[0.0001]$} & {$[0.0001]$} & {$[0.0034]$} & {$[0.0001]$} & {$[0.0001]$} & {$[0.0001]$} & {$[0.0001]$} \\
\hline \multirow[t]{2}{*}{ Primary Education } & -0.0000 & -0.0000 & -0.0000 & $-0.0046^{*}$ & -0.0000 & -0.0000 & -0.0000 \\
\hline & {$[0.0001]$} & {$[0.0001]$} & {$[0.0001]$} & {$[0.0025]$} & {$[0.0001]$} & {$[0.0001]$} & {$[0.0001]$} \\
\hline \multirow[t]{2}{*}{ Household size } & 0.0000 & 0.0000 & 0.0000 & 0.0000 & 0.0000 & 0.0000 & 0.0000 \\
\hline & {$[0.0000]$} & {$[0.0000]$} & {$[0.0000]$} & {$[0.0000]$} & {$[0.0000]$} & {$[0.0000]$} & {$[0.0000]$} \\
\hline Close networks abroad & $0.0004^{* * *}$ & $0.0004^{* * *}$ & $0.0004^{* * *}$ & $0.0004^{* * *}$ & $0.0004^{* * *}$ & $0.0004^{* * *}$ & $0.0145^{* *}$ \\
\hline wpoor & {$[0.0000]$} & {$[0.0000]$} & {$[0.0000]$} & {$[0.0000]$} & {$[0.0000]$} & {$[0.0026]$} & {$[0.0000]$} \\
\hline \multirow[t]{2}{*}{ Large city } & $0.0003^{*}$ & $0.0003^{*}$ & $0.0003^{*}$ & $0.0003^{*}$ & $0.0003^{*}$ & $0.0003^{*}$ & $0.0003^{*}$ \\
\hline & {$[0.0001]$} & {$[0.0001]$} & {$[0.0001]$} & {$[0.0001]$} & {$[0.0001]$} & {$[0.0001]$} & {$[0.0001]$} \\
\hline \multirow[t]{2}{*}{ Satisfaction with the city/area } & $-0.0003^{* * *}$ & $-0.0003 * * *$ & $-0.0003^{* * *}$ & $-0.0003 * * *$ & $-0.0003^{* * *}$ & $-0.0003^{* * *}$ & $-0.0003 * * *$ \\
\hline & {$[0.0001]$} & {$[0.0001]$} & {$[0.0001]$} & {$[0.0001]$} & {$[0.0001]$} & {$[0.0001]$} & {$[0.0001]$} \\
\hline \multirow[t]{2}{*}{ Distance*female } & & 0.0009 & & & & & \\
\hline & & {$[0.0006]$} & & & & & \\
\hline \multirow[t]{2}{*}{ Distance*Youth $(<35)$} & & & $-0.0007^{*}$ & & & & \\
\hline & & & {$[0.0004]$} & & & & \\
\hline \multirow[t]{2}{*}{ Distance*Primary education } & & & & $0.0005^{*}$ & & & \\
\hline & & & & {$[0.0003]$} & & & \\
\hline OriginX2012 FE & Yes & Yes & Yes & Yes & Yes & Yes & Yes \\
\hline DestinationX2012 & Yes & Yes & Yes & Yes & Yes & Yes & Yes \\
\hline Pair FE & Yes & Yes & Yes & Yes & Yes & Yes & Yes \\
\hline
\end{tabular}

Notes: The dependent variable is a binary indicator for positive bilater migration intention. Results are estimated with a linear probability model. All regressions include a set of country-pair and country-year fixed effects. Standard errors clustered at the level of origin country and country-pair are reported in brackets. ${ }^{* * *} \mathrm{p}<0.01,{ }^{* *} \mathrm{p}<0.05,{ }^{*} \mathrm{p}<0.1$

agreements that led to the closure of the Balkan route. The Gallup polls we have used could also be complemented by more systematic surveys among refugees in the host countries. 
Table 8: Heterogenous effects by individual skill-level

\begin{tabular}{lc}
\hline VARIABLES & \\
\hline & \\
Smuggling distance & $-0.0047^{*}$ \\
& {$[0.0026]$} \\
Secondary education & $0.0050^{*}$ \\
& {$[0.0026]$} \\
Tertiary education and above & 0.0003 \\
& {$[0.0022]$} \\
Distance*secondary education & $-0.0006^{*}$ \\
& {$[0.0003]$} \\
Distance*tertiary education & -0.0000 \\
& {$[0.0002]$} \\
& \\
\hline Observations & $1,217,159$ \\
OriginX2012 FE & Yes \\
DestinationX2012 FE & Yes \\
Pair FE & Yes \\
\hline
\end{tabular}

Notes: The dependent variable is a binary indicator for positive bilater migration intention. Results are estimated with a linear probability model. All regressions include a set of individual controls as in Table 5 plus country-pair and country-year fixed effects. Standard errors clustered at the level of origin country and country-pair are reported in brackets. ${ }^{* * *} \mathrm{p}<0.01,{ }^{* *}$ $\mathrm{p}<0.05,{ }^{*} \mathrm{p}<0.1$

\section{References}

Akee, R., Basu, A. K., Bedi, A., and Chau, N. H. (2014). Transnational trafficking, law enforcement, and victim protection: A middleman trafficker's perspective. The Journal of Law and Economics, $57(2): 349-386$.

Arcand, J.-L. and Mbaye, L. (2013). Braving the waves: The role of time and risk preferences in illegal migration from senegal. IZA Discussion Papers 7517, Institute for the Study of Labor (IZA).

Auriol, E. and Mesnard, A. (2016). Sale of visas: a smuggler's final song? Economica, 83(332):646678.

Beine, M., Bertoli, S., and Fernández-Huertas Moraga, J. (2015). A practitioners' guide to gravity models of international migration. The World Economy, 39(4):496 - 512.

Beine, M., Docquier, F., and alarzden (2011). Diasporas. Journal of Development Economics, 95(1):30 - 41. Symposium on Globalization and Brain Drain.

Borjas, G. (1987). Self-selection and the earnings of immigrants. American Economic Review, $77(4): 531-553$.

Borjas, G. (1999). The economic analysis of immigration. In Ashenfelter, O. C. and Card, D., editors, Handbook of Labor Economics, pages 1697-1760. Amsterdam: North-Holland.

Brücker, H., Capuano, S., and Marfouk, A. (2013). Education, gender and international migration: Insights from a panel-dataset 1980-2010. mimeo.

Chiquiar, D. and Hanson, G. H. (2005). International migration, self-selection, and the distribution of wages: Evidence from mexico and the united states. Journal of Political Economy, 113(2):239281. 
Cho, S.-Y., Dreher, A., and Neumayer, E. (2014). Determinants of anti-trafficking policies: Evidence from a new index. The Scandinavian Journal of Economics, 116(2):429-454.

Clemens, M. (2011). Economics and emigration: Trillion-dollar bills on the sidewalk? Journal of Economic Perspectives, 25(3):83-106.

Creighton, M. J. (2013). The role of aspirations in domestic and international migration. The Social Science Journal, 50(1):79-88.

Disdier, A. C. and Head, K. (2008). The puzzling persistence of the distance effect on bilateral trade. Review of Economics and Statistics, 90(1):37-48.

Docquier, F., Peri, G., and Ruyssen, I. (2014). The cross-country determinants of potential and actual migration. International Migration Review, 48(S1):S37-S99.

Dolfin, S. and Genicot, G. (2010). What do networks do? the role of networks on migration and "coyote" use. Review of Development Economics, 14(2):343-359.

Dustmann, C. and Okatenko, A. (2014). Out-migration, wealth constraints, and the quality of local amenities. Journal of Development Economics, 110:52-63.

Esipova, N., Ray, J., and Pugliese, A. (2011). Gallup World Poll: the many faces of global migration. IOM Migration Research Series, No. 43.

Feyrer, J. (2009). Distance, trade, and income - the 1967 to 1975 closing of the suez canal as a natural experiment. NBER Working Papers 15557, National Bureau of Economic Research, Inc.

Friebel, G. and Guriev, S. (2006). Smuggling humans: A theory of debt-financed migration. Journal of the European Economic Association, 4(6):1085-1111.

Friebel, G. and Guriev, S. (2012). Human smuggling. IZA Discussion Papers 6350, Institute for the Study of Labor (IZA).

Gallup (2012). Worldwide research methodology and codebook.

Gathmann, C. (2008). Effects of enforcement on illegal markets: Evidence from migrant smuggling along the southwestern border. Journal of Public Economics, 92(10-11):1926-1941.

Hanson, G. (2004). Illegal migration from Mexico to the United States. Journal of Economic Literature, Vol. 44(4):869-924.

Hanson, G. (2007). The economic logic of illegal immigration. Council special report n.26, Council on Foreign Relations.

Head, K. (2014). Gravity equations: Workhorse, toolkit, and cookbook. Handbook of International Economics, 4:131.

Jandl, M. (2007). Irregular migration, human smuggling, and the eastern enlargement of the european union. International Migration Review, 41(2):291-315.

Lucas, R. (2001). The effects of proximity and transportation on developing country population migrations. Journal of Economic Geography, 1(3):323-39.

Mahmoud, T. O. and Trebesch, C. (2010). The economics of human trafficking and labour migration: Micro-evidence from eastern europe. Journal of Comparative Economics, 38(2):173-188. 
Martin, P. and Miller, M. (2000). Smuggling and trafficking: a conference report. International Migration Review, 34(3):969-975.

Mayda, A. M. (2010). International migration: A panel data analysis of the determinants of bilateral flows. Journal of Population Economics, 23(4):1249-1274.

Ortega, F. and Peri, G. (2013). The effect of income and immigration policies on international migrations. Migration Studies, 1(1).

Pascali, L. (2017). The wind of change: Maritime technology, trade, and economic development. American Economic Review, 107(9):2821-54.

Salt, J. (2003). Current trends in international migration in europe. Report, Strasbourg: Council of Europe.

Shelley, L. (2014). Human smuggling and trafficking into europe: A comparative perspective. Technical report, Migration Policy Institute.

Sjaastad, L. (1962). The costs and returns of human migration. Journal of Political Economy, 70(5):80-93.

Spilimbergo, A. and Hanson, G. (1999). Illegal immigration, border enforcement, and relative wages: Evidence from apprehensions at the u.s.-mexico border. American Economic Review, 89(5):1337-1357.

Tamura, Y. (2010). Migrant smuggling. Journal of Public Economics, 94(7):540 - 548.

Tinbergen, J. (1962). Shaping the world economy; suggestions for an international economic policy. Books (Jan Tinbergen).

UNODC (2011). Smuggling of migrants: A global review and annotated bibliography of recent publications. Report, UNITED NATIONS OFFICE ON DRUGS AND CRIME.

van Dalen, H. P. and Henkens, K. (2008). Emigration intentions: Mere words or true plans? Explaining international migration intentions and behavior. Discussion paper, http://ideas . repec. org/p/dgr/kubcen/200860.html.

van Dalen, H. P. and Henkens, K. (2013). Explaining emigration intentions and behaviour in the Netherlands, 2005-2010. Population Studies, 67(2):225-241. 